\title{
Critical Thinking, Communications, and Teamwork
}

\author{
Terrence L. Freeman \\ St. Louis Community College at Florissant Valley
}

\section{Introduction}

The last quarter of the twenty-first century has witnessed a time of accelerating change and increasing complexity. One of the complexities is the change in demographics that employers and academic institutions are experiencing. Another complexity is the changing nature of work. Today's graduate can anticipate several job and/or career changes before retirement. Beyond technical competence, employers consistently rank communication skills, teamwork, creative thinking, and problem solving as the primary skills that they seek in prospective employees ${ }^{1}$. Beyond employment, these traits could be defined as critical success skills for a rapidly changing world. Collaborative education is one approach that institutions of higher education can utilize within the curriculum to develop and reinforce these skills. The study habits of team members and how they are assigned to functional teams have a strong impact on skill development. Effective high performing teams have a clear mission, are results driven, are committed to team success, operate in a climate of trust and collaboration, maintain standards of excellence, and demonstrate good communication skills ${ }^{2}$. In order to help students progress in the "buzz word" areas of critical thinking, communication and teamwork, it may be helpful to explore related topics such as coping with change, establishing interdependent relationships, valuing diversity, managing stress, overcoming negativity, thinking creatively, sustaining motivation, and maintaining resilience.

\section{Beyond Critical Thinking}

Most activities do not require creative thinking or application. Habit and routine are generally more than sufficient to accomplish day-to-day tasks and challenges. Too many people accept the notion that they are not creative, and that the best ideas belong to other people. Sometimes, creative thinking is equated with intelligence. Intelligence alone, however, does not assure good thinking. Intelligence may be more aptly associated with the capacity for creative thought rather than the extent to which that capacity is utilized. Knowledge may be the foundation of the creative thought process, but knowledge is not what makes a person creative. Critical thinking is emphasized frequently as a goal in education, but the ability to think critically is only one dimension of the creative thought process that students should develop. Creative thinking requires an attitude and an approach to manipulating knowledge and experience that facilitates the development of new ideas. The key is thinking about knowledge in new ways. Creative thinking can be taught and reinforced, but the process demands more from students and teachers than memorization and regurgitation of facts and formulas.

Debono (1995) describes a dozen diagnostic, analytical, and evaluative processing skills that contribute to creative thinking ${ }^{3}$ : (1) recognition, (2) interpreting clues, (3) concept formation, (4) generating possibilities, (5) judgment, (6) developing alternatives, (7) comparison \& choice, (8) analysis, (9) perception, (10) values \& feelings, (11) design, and (12) problem solving. 
Von Oech outlines several factors that tend to diminish how effectively students perform as creative thinkers ${ }^{4}$. One stumbling block is the often mistaken idea that there is only one right answer. While this may be true for relatively simple math problems, it is not the case for many of the complex problems students will face in the twenty-first century. Having a blind allegiance to the "rules" often prevents a thinker from exploring all the possibilities. Adhering to the artificial constraints that demand logic and seriousness while prohibiting foolishness and playfulness may destroy any opportunity for a breakthrough idea. In creative thinking ambiguity is far from fatal, and mistakes may, in fact, be helpful if students are prepared to learn from them. Creative thinking is not a linear process and the elements discussed in this paper are not sequential steps. It is important to have these processing skills available at all times and through all the steps that may be suggested in a problem solving or design strategy. Preparing students to be more creative thinkers is a matter of helping them understand that creative thinking is much broader than critical thinking. To the extent that faculty and staff provide opportunities for students to practice many of these skills in and outside of the classroom, students will become better thinkers and ultimately better problem solvers.

\section{Coping with change}

Today's student is living in a time of accelerating change and complexity. A central truth is that change happens to everyone and the extent of the change is frequently beyond the control of the individual. Geopolitical systems, the environment, families and communities, and health concerns are just some of the changes in the twenty-first century landscape. Students are facing immediate concerns with rapidly evolving technology, shifting demographic patterns and changes in the nature of work. Change creates challenges and stress that can only be resolved by the choices made by an individual or a group. Unfortunately, much of the twenty-first century change will be non-linear, discontinuous, and unpredictable. The primary challenge for the twenty-first century student will be developing the intellectual and emotional traits and abilities that entail excellence in responding to conditions of change.

Celente (1997) discusses some of the demographic change that will continue to impact life and work in the twenty-first century United States ${ }^{5}$. Millions of immigrants have come to the United States in the last two decades and there is no typical immigrant profile. Although there has been a large influx of undereducated and unemployed immigrants, there has also been a net "brain gain." Writers, artists, and filmmakers, along with the world's scientific elite have contributed to making the United states the technological and cultural capital of the world. At the same time, approximately half of all children in single parent families live in poverty. In the last three decades the percentage of white children in single parent families has tripled and the number of black children living with one parent has doubled. The fastest growing segment of the U.S. population is the one over 85 years of age and only $25 \%$ of that group can live alone without difficulty. More women are entering the workforce and even more significantly many of them are also mothers. The proportion of two-income families has almost doubled since 1960. The "sandwich generation" is being forced to choose between nursing home fees for parents and college tuition for children. Increasing family-work conflicts result in lower productivity along with higher turnover, stress, and distraction. As a result of many of these demographic changes

the percentage of the workforce that is non-Hispanic white male has declined from $60 \%$ in 1960

"Proceedings of the 2001 American Society for Engineering Education Annual Conference \& Exposition Copyright (C) 2001, American Society for Engineering Education" 
to roughly $40 \%$ today. By 2030 one-third of the U.S. population will be over the age of 65 . In this changing environment, students will be challenged to develop better skills in communicating and cooperating across demographic barriers. Colleges and universities have an opportunity, if not an obligation, to facilitate the development of cross-cultural skills among their students.

Rifkin (1995) outlines how the impact of technology on the American worker has continued to evolve over the past two hundred years ${ }^{6}$. At the beginning of the nineteenth century farming was the primary occupation and machines were not yet significant in reducing manual labor. By the mid-1800s inventions like the reaper, the steel plow and the tractor reduced the percentage of the national labor force involved in agriculture from $75 \%$ to a little over $30 \%$ in 1900 . By 1940 the figure was $20 \%$ and today it is less than $3 \%$. By contrast only 75,000 persons were employed in what could be considered manufacturing in 1810 and that number grew to over 8 million by 1910. Manufacturing peaked at $35 \%$ of the labor force as technology continued to leave its imprint. Between 1960 and 1990, manufacturing output continued to rise, but the number of jobs needed to sustain that output was cut in half. While large companies released record numbers of employees, small companies picked up the employment slack. Less than $1 \%$ of U.S. companies employ more than 500 workers, but these large corporations still account for $40 \%$ of the workers in the private sector. Typically new technologies boost productivity, lower production costs, expand markets and increase employment. The technologies of the information and communication revolution are changing the very nature of work. Boyett (1995) describes the impact of changing technology on the workplace ${ }^{1}$ :

Perhaps more importantly, the new technology has done something that was considered impossible in the past. It set information free from time and space. Now, the same information can be distributed instantly to widely different places at precisely the same time. That makes it unnecessary for people who must work together and share information to be physically located in the same place, and it makes it possible for many more people to be involved in working on a project or solving a problem . . . Demands for creativity and innovation are driving American companies to create this new kind of organization. Technology is making this new organization possible. It is also changing the workplace in revolutionary ways. Working will never again be the same. It isn't just a new workplace. It is a new world, where traditional notions of work and leisure and the employee and employer are no longer valid. (p. 75)

In order to cope with change, it is necessary to understand something about the dynamics of the change process. Change is difficult for most people and consequently, change is met with resistance. Change tends to disrupt an established comfort zone or frame of reference. Managing change effectively means making a deliberate choice to embrace new frames and develop new comfort zones. Change can be disorienting and because of the number of changes the world is witnessing, most people will continually find themselves in some stage of transition. To the extent that the individual uses change as a catalyst for the creative process, the disorienting impact of change can be minimized.

The academic arena needs to prepare students to embrace and manage change. Providing students with the opportunity to work in diverse teams can challenge them to develop stronger interpersonal and cross-cultural communication skills. Activities can be designed for students to use a collaborative approach in response to change by asking them to

"Proceedings of the 2001 American Society for Engineering Education Annual Conference \& Exposition Copyright (C) 2001, American Society for Engineering Education" 
1. Define a current situation.

2. Diagnose the nature and impetus for change.

3. Accept responsibility for developing a response.

4. Determine potential positive and negative consequences of the change.

5. Develop alternative response paths to the change.

6. Select an appropriate course of action.

7. Keep an optimistic outlook.

8. Review, evaluate, and adjust the approach as needed.

Students can apply these questions with some modification to technological changes that have already occurred. They can also be asked to examine the possible impact of a new technology. Whether this activity is a short collaborative research paper, a panel discussion, extra credit assignment, or extra-curricular activity, students need to develop a strategic response to change.

\section{Diversity}

Gay (1994) discusses some of the challenges in educating a diverse student body ${ }^{7}$. She notes that many educators operate under the faulty assumption that principles of good pedagogy determine what knowledge is desirable and how it can best be taught. Culture influences and shapes all dimensions of the learning and teaching processes utilized in academia and every action is unavoidably culture-bound. The demographic changes in the United States along with persistent racial tensions suggest that cultural diversity is increasingly a normative description of U.S. society. Diversity, however, is much broader than race, ethnicity, gender, or age. With the flow of information, jobs, capital, and people no longer respecting geographic boundaries, it would be imprudent to ignore diversity in the education of students.

\section{Effective communication}

Employers continually emphasize the need for strong communication skills. The twenty-first century employee or entrepreneur in engineering and technology will participate in presentations, collaborations, one-on-one communications, research, design, and report writing. The ability to communicate orally and in writing is central to the ability to achieve success. Unfortunately, students tend to shy away from activities where they lack skill or confidence. The only way to overcome their discomfort is through good practice. Practice is the art of moving from uncomfortable to comfortable and completing this transition generally means doing something uncomfortable in between. The curriculum should reinforce critical communication skills in a manner that ensures that graduates of a program can communicate effectively. The emphasis on communication should be spread across the curriculum, and the importance to the student should be emphasized. Emphasizing the importance of communication without demanding it in each academic course may send conflicting signals to the students.

There are three general areas of emphasis in helping students with communications: listening, writing, and speaking. The quality of written communication is generally judged by content, organization, correctness, and appearance. The correctness and appearance of a document depend on spelling, grammar, and the use of word processing. Most schools have writing labs and word processors are fairly sophisticated. The content and organization of a report depend on the purpose and reader. The quality of writing will improve if faculty in every course demand 
that students submit several word processed reports. It is also important that students be given a preferred format, the reader for whom the report is prepared, and criteria for how the report will be graded. Assigning regular short reports with an opportunity to re-write will accomplish more than the semester-long "monster report" that visits pain and angst on students and faculty. Writing can also be reinforced by placing process essay questions on tests, or by asking students to keep journals on design projects. The goal is to help students embrace writing and develop confidence in their abilities.

Oral communication occurs far more frequently than written communication. Interpersonal oral communication may not generate the same level of anxiety that a formal presentation does, but it is not a skill to be overlooked. Interpersonal communication is where relationships are developed and sustained. Effective interpersonal communication demands a willingness to listen for understanding rather than to critique or debate. Listening empathetically allows the listener to come closer to what the speaker thinks, sees, or feels. Good listening also requires an appreciation for the cultural and experiential diversity that may influence the communication process. Active listening is hard work and it requires considerable concentration. Faculty can periodically give listening quizzes where students listen, without taking notes, to a short courserelated passage followed by a quiz on the contents.

Group communication adds a layer of complexity to interpersonal communication. In group communication, people are brought together to accomplish a task or complete a project. The participants are faced with the "three C's of effective group dynamics": collaboration, consensus and compromise ${ }^{8}$. Mastering these skills is critical to success in the business, engineering, and technology setting and these skills should be reinforced in the academic setting as well. Students should be given the opportunity to work in groups which challenge them to develop these skills. This means placing them on occasion in groups in which they have no pre-existing comfort level.

The formal presentation is the one that meets with the greatest resistance among students. The quality of a formal presentation is based on content and delivery. Both of these require some knowledge about the audience and the purpose of the presentation. Effective delivery centers around focus, energy, and clarity. The hardest part of a formal presentation for many students is standing in front of an audience. It is difficult to work presentations into an already packed course schedule, but there are some activities that can help. The frequency of making a presentation is more important than the length in overcoming anxiety. Faculty can ask students to prepare thirty second introductions that they will deliver to the rest of the class instead of taking attendance on the first day. Although it takes more time, the faculty and the students come away with a greater sense of who is in the class and why. Students can also be asked to give one minute presentations on topics that are relevant to course content throughout the semester. These exercises can also be used to reinforce the listening skills of the class. Extra credit can be assigned for students who speak on course related topics in an extra-curricular environment.

The focus of the suggested activities is not to cram more into a semester. If faculty can find alternatives to content delivery that reinforce communication skills, then students are better served. Since communication skills are critical to the success of students in the business and technical world, it is a service that academia should strive to provide.

"Proceedings of the 2001 American Society for Engineering Education Annual Conference \& Exposition Copyright (C) 2001, American Society for Engineering Education" 


\section{Teambuilding - Establishing interdependent networks and relationships}

The ability to communicate effectively and the commitment to value diversity are important elements of teamwork, but students still need a functional understanding of group dynamics. Katzenbach and Smith (1994) discuss some of the keys in developing effective teams ${ }^{2}$. The ultimate goal of the team is performance, and that requires an appreciation of what is required to collaborate, compromise and reach consensus. In order for a team to operate at a high level of performance it has to have a clear understanding of the mission and goals of the team. They must also develop a simultaneous commitment to the collaborative team concept as well as a commitment to results. Having high standards and being results driven may be necessary attributes for a high performance team, but they are not sufficient. Being on a team is not the same as believing in the team or being prepared to utilize its strength. Moving from a group of individuals to a functioning team requires good communication and trust. Ultimately, the enduring success of a team depends on the quality of the relationships developed within the team.

Functioning in a team is more than coming together to complete a project. It is not enough to assign students to a team and give them a task. One of the purposes of any group assignment should be to help students develop some of the skills required for effective teamwork. For that reason faculty should provide some guidance and an opportunity for groups to become teams. Encouraging them to clarify their mission, establish their mutual interests and goals, and build rapport is a good start ${ }^{9}$. Hunkeler and Sharp (1997) recommend that students be assigned to functional groups rather than allowing group formation through random or self-selection processes $^{10}$. This requires some level of assessment prior to group formation. They report that the optimal group size is four students and that academically strong students should be evenly distributed among the groups. They also encourage an even distribution of students with practical experience. The distribution of gender, learning styles, and cultural and social differences may have some impact on group performance, but their research did not determine the extent of the impact. They did raise a concern that cliques or sub-groups could undermine the functionality of the team and that possibility should be monitored.

\section{Overcoming negativity}

Negative people unconsciously limit their own abilities, discourage teamwork, and sabotage the results that could be achieved. Students frequently find themselves succumbing to or surrounded by negativity, and that works against creative thought and accomplishment. The sources of negative beliefs, attitudes, and perceptions vary among individuals and organizations. Negativity may result from personal dysfunction, stress, cross-cultural collisions, or dysfunctional teams and organizations. Negativity does not always present itself in the expected form of overt negativity. Carter-Scott (1989) describes four general types of "negaholics": (1) attitudinal, (2) behavioral, (3) mental, and (4) verbal ${ }^{11}$. In order to be an effective member of a team, negativists need to recognize and control the tendency toward negativity.

In the academic arena faculty and staff have an opportunity to help students recognize their potential for achieving goals and making a positive impact on a team effort. The academic experience should not be designed, by intent or accident, to strip positive self-regard from 
students. The academic experience teaches more than course content, and one of the lessons should be for students to develop a level of trust in their ability to contribute. Faculty and staff can help students develop support systems in which they are part of team that is committed to each member's well-being and empowerment. An academic program can help students move beyond negativity when it experientially encourages students to

- Pursue their dreams and goals

- Seek guidance and support for their objectives

- Believe in themselves

- Be prepared to believe in others

- Focus on solutions rather than problems

- Assume responsibility for their behavior and actions

- Learn and grow from their experience

Unfortunately, when academic barriers seem insurmountable, when faculty are unapproachable, when rationale is unexplained, or when risk-taking is punished while growth goes unrecognized, the college experience works to increase the negativity that students carry. If students can successfully complete academic programs without shedding their negativity, the troubling outcome may be a technically competent but creatively malnourished work force. More should be expected from the academic community.

\section{Stress management}

Charleworth and Nathan (1984) describes stress as a physical or psychological disruption resulting from the application of some stressor ${ }^{12}$. He goes on to define stressors as anything that threatens, prods, frightens, worries, tenses, thrills, or keys up the body in any way. A rigorous academic program can induce stress and some students are overwhelmed in the process. Unfortunately the ability to endure stress is worn like a badge of honor by those who have survived the ordeal. The looming question is whether or not an academic program should provide some level of student instruction on how to use moderate levels of stress to stimulate productivity while retreating from the excessive levels of stress that can lead to failure. Students should be encouraged to question how they are served by stressful situations and what they can learn from them. They need to focus on those things that they can control and they need to learn to let go of those things that are beyond their control. Faculty and staff can encourage students to brainstorm options and look for opportunities in crisis situations. The key is to develop skills that can be applied under stress by practicing them before the stress arrives. If persistence and student retention is a goal, the academic program should help students learn to manage stress effectively rather than merely selecting and rewarding those students who have learned to do so on their own.

\section{Sustaining motivation}

Motivation is popularly described as the forces that act on or within the individual which initiate behavior and give it direction. Small (1998) describes many of the theories of motivation ${ }^{13}$. Rogers suggests that motivation is generated by the need for unconditional positive regard. Deci sees the need as self-determination. McClelland considers achievement as the primary need while Atkinson combines the needs of achievement and failure avoidance. Small goes on to discuss theorists who operate from a cognitive perspective where motivation is learned and not 
driven by need. Expectancy theory suggests that people are motivated when they feel that effort improves performance and performance leads to desired outcomes. Some of the commonalties of these theories are that motivation is highest when people are competent, have sufficient autonomy, set worthwhile goals, get feedback, and are affirmed by others. It seems that real and sustainable motivation is internally driven, but that drive needs to be externally supported and encouraged.

Students often struggle with motivation and the struggle is particularly challenging in the rigors of an engineering or technology program. Faculty, counselors, and advisors can help students set challenging and realistic goals, but they can also help students to build a success support team. The four types of people on this team are mentors, coaches, practice partners, and cheerleaders. Mentors have achieved the goal that the student has set. They can provide tangible personal evidence that the goal can be achieved in addition to real insight on what it takes to do so. Coaches may not have achieved the goal, but they possess a critical eye and are good at providing feedback on how well a student is executing the game plan for achieving success. Practice partners may not have the insight of a coach, but they are in the 'same boat' and that gives them a genuine appreciation of what their dream teammates are experiencing. Cheerleaders are those people who have a genuine interest in seeing a student succeed even if they can't fully appreciate the challenges faced by the student. Forming this team can help a student obtain the feedback and sustain the energy necessary to achieve a challenging goal.

\section{Resilience through Humor.}

Sultanoff (1997) describes resilience as the ability of the human organism to spring back from stressors in the environment ${ }^{14}$. He goes on to suggest that humor can be an important contributor to creative thinking. Since it involves the escape from one pattern of thinking to another and it can help build physical and emotional resilience by changing thoughts, feelings, and behaviors. The average child laughs about 400 times a day while the average adult laughs about 15 times a day $^{15}$. Too often, the transition to adulthood means becoming more serious, more focused, more logical, more rigid, and so respectful of knowledge and experience that creative thinking is sacrificed. The more a person experiences humor, the more that person is likely to greet and connect with others. It would be a mistake to confuse serious creative thought and problemsolving with maintaining a serious demeanor. Vance and Deacon ${ }^{15}$ assert that "high-level creativity and thinking out of the box occur when people are free enough to have fun." (p. 144)

\section{Summary}

Students are faced with a rapidly changing world and pure content in any curriculum will be insufficient in preparing them for this future. Colleges and universities are challenged to prepare their students for the total process of living as well-adjusted, intellectually competent, and selfdetermining individuals. This means educating the whole student above and beyond technical competency. It is easy to fall into the trap that educators are only responsible for content and that the synthesis of life-long learning and productivity skills is solely the responsibility of the student. Engineering and technology are creative thought enterprises. When the environment changes the creative thinker utilizes a variety of skills to fashion alternatives and select effective responses to the change. The same level of creative thinking, communication, and teamwork that 
is demanded by the engineering and technology enterprise should be applied to the education process. There are numerous responses to this challenge, but the least serious is applying yesterday's approach to engineering and technology education without seriously considering whether or not there are better alternatives.

\section{Bibliography}

1. Boyett, J.H. and J.T. Boyett, Beyond Workplace 2000: Essential Strategies for the New American Corporation. 1995, New York: Dutton. 298.

2. Katzenbach, J.R. and D.K. Smith, The Wisdom of Teams: Creating the High-Performance Organization. 1994, New York: HarperCollins. 317.

3. de Bono, E., Edward de Bono's Mind Power. 1995, New York: Dorling Kindersley. 72.

4. Von Oech, R., A Whack on the Side of the Head. Revised ed. 1990, New York: Warner Books. 196.

5. Celente, G., Trends 2000: How to Prepare for and Profti from the Changes of the 21st Century. 1997, New York: Warner Books. 337.

6. $\quad$ Rifkin, J., The End of Work. 1995, New York: G. P. Putnam's Sons. 350.

7. Gay, G., A Synthesis of Scholarship in Multicultural Education. 1994, NCREL Urban Education Monograph Series. http://www.shss.montclair.edu/english/classes/stuehler/engl105/leogay.html

8. Cheshier, S.R., Studying Engineering Technology: A Blueprint for Success. 1998, Los Angeles: Discovery Press. 297.

9. Hunsaker, P.L. and A.J. Alessandra, The Art of Managing People. 1980, New York: Simon and Schuster Inc. 270.

10. Hunkeler, D. and J. Sharp, Assigning Functional Groups: The Influence of Group Size, Academic Record, Practical Experience, and Learning Style. Journal of Engineering Education, 1997. 86(4): p. 321-332.

11. Carter-Scott, C., Negaholics: How to Overcome Negativity and Turn Your Life Around. 1989, New York: Fawcett Crest. 236.

12. Charlesworth, E.A. and R.G. Nathan, Stress Management: A Comprehensive Guide to Wellness. 1984, New York: Ballantine Books. 400.

13. Small, R.V., Designing Motivation into Library and Information Skills Instruction. 1998, American Library Association. http://www.ala.org/aasl/SLMQ/small.html

14. Sultanoff, S.M., Survival of the Witty-est: Creating Resilience through Humor. Therapeutic Humor, 1997. 11(5): p. 1-2.

15. Vance, M. and D. Deacon, Think Out Of The Box. 1995, Franklin Lakes, NJ: Career Press. 216.

\section{TERRENCE L. FREEMAN}

Terrence L. Freeman is an Associate Professor of Mechanical Engineering at St. Louis Community College at Florissant Valley. He graduated from Rensselaer Polytechnic Institute with a B.S. in Mechanical Engineering and received a M.S. from Massachusetts Institute of Technology. He is currently the Engineering Science Coordinator at Florissant Valley and has served as the has served as Coordinator of the Minority Engineering Transfer Program. 